Revista de Direito, Inovação, Propriedade Intelectual e Concorrência

\title{
A ATUAÇÃO DO INPI NOS PROCESSO DE NULIDADE E ABSTENÇÃO DO USO DE MARCA SOB A ÓTICA NO NOVO CÓDIGO DE PROCESSO CIVIL
}

\author{
Almir Garcia Fernandes ${ }^{1}$
}

\section{Resumo:}

Esse estudo tem por finalidade analisar questões relacionadas aos julgamentos que envolvem nulidade e abstração do uso de marcas, especialmente sobre a forma de intervenção do INPI nesses processos. Pretende-se demonstrar através do método dedutivo que mesmo com a promulgação de um novo Código de Processo Civil, não há ainda uma modalidade de intervenção de terceiro que seja adequada à exigência da Lei 9.279/96, devendo ser considerada uma intervenção inominada

Palavras-chave: Marca registrada; nulidade de registro; intervenção de terceiros; processo civil; pesquisa dedutiva

\section{THE INPI'S PERFORMANCE IN THE NULLITY PROCESS AND ABSTENTION OF THE USE OF THE BRAND UNDER THE OPTICS IN THE NEW CIVIL PROCESS CODE}

\begin{abstract}
:
This study aims to analyze issues related to judgments that involve nullity and abstraction from the use of trademarks, especially regarding the form of INPI intervention in these processes. It is intended to demonstrate through the deductive method that even with the promulgation of a new Code of Civil Procedure, there is not yet a third party intervention modality that is adequate to the requirement of Law 9.279 / 96, and should be considered an unnamed intervention
\end{abstract}

Keywords:Trademark; nullity of registration; third party intervention; civil process; deductive research

\footnotetext{
${ }^{1}$ Professor de Direito Civil e Empresarial na Universidade Federal de Uberlândia. Doutor em Direito Comercial pela PUC de São Paulo. Mestre em Direito das Relações Econômico-Empresariais pela Universidade de Franca. almirgarcia@ufu.br
} 


\section{INTRODUÇÃO.}

As marcas pertencem ao grupo dos sinais distintivos da atividade empresarial inseridos em produtos e serviços ofertados por empresários à sua clientela, com finalidade de diferenciálos de seus concorrentes.

Seu processo de registro é feito perante o Instituto Nacional da Propriedade Industrial - INPI - único órgão habilitado a fazer esse tipo de registro, após o qual o empresário adquire o direito de utilização exclusiva, restrito a uma determinada classe de produtos ou serviços.

Após registrada, a marca tem o potencial de transcender aos produtos ou serviços que representa, dando segurança, status, confiabilidade, tanto àquele que adquire ou contrata, quanto ao próprio empresário. Ao mesmo tempo, gera individualização e distinção, podendo conter elementos visualmente perceptíveis, gráficos, figurativos, plásticos, fotográficos, que lhe diferencia de outros sinais do próprio empresário, como de seus concorrentes.

A globalização econômica e o exponencial desenvolvimento dos meios de comunicação acabou por facilitar o acesso de consumidores de diferentes regiões a produtos e serviços que são oferecidos por diferentes empresas. Em virtude disso, tornaram-se cada vez mais comuns as situações práticas em que os empresários encontram semelhanças de suas marcas ou de seus elementos visuais não só por terceiros não autorizados, "free rides", mas também em outras marcas igualmente registradas no INPI.

Por isso, não são raros os processos judiciais que tem como ponto principal pedidos de abstenção de terceiros de uso de marca já anteriormente registrada, seja pela utilização indevida e sem autorização do titular, ou em situações de semelhanças entre marcas registradas que podem causar confusão aos destinatários finais dos produtos ou serviços, gerando assim prejuízos ao titular da marca.

O estudo que este artigo se propõe está direcionado aos processos judiciais em que se discute a nulidade e a abstenção de uso de marca, em especial na modalidade de intervenção do INPI, pois o art. 175 da Lei 9.279/96 determinou que os processos de nulidade de registro de marca em que o INPI não for autor, ele deverá obrigatoriamente intervir, entretanto, não indicou expressamente qual é a modalidade de intervenção de terceiros. Ainda, não há indicação da necessidade de intervenção do INPI em processos de abstenção do uso de marcas que não envolvam a nulidade. 
A modalidade de intervenção do INPI nos processos de nulidade de marcas passou a ser uma questão polêmica desde a promulgação da lei 9.279/96 quando o legislador optou por determinar que o INPI não seria litisconsorte, mas sim interventor nas ações de nulidade de registro de marca. Essa discussão acabou por remontar a diversas decisões judiciais que ora incluíam o INPI como assistente simples, ora como assistente litisconsorcial, sem, contudo, ofertar uma solução definitiva ao caso.

Com a promulgação do novo Código de Processo Civil, novas modalidades de intervenção de terceiros foram incluídas no texto da Lei 13.105/2015, o que impõe a necessidade de um estudo mais atual sobre o tema.

Ainda, quanto à competência, não há qualquer dúvida sobre a competência da Justiça Federal para processar e julgar as ações de nulidade de registro de marca, contudo, paira a dúvida quanto a competência para o julgamento de ações de abstenção do uso de marca ou mesmo das ações que visam coibir a concorrência desleal entre empresários que não visam a nulidade de registro.

Isso porque em alguns casos a violação da marca, no todo ou em parte, poderá estar sendo feita por outra marca registrada no INPI, seja pela extrapolação do princípio da especialidade da marca do infrator ou mesmo por usar elementos que compõe o trade dress da marca violada, qual seja o conjunto de elementos que pode causar confusão ao destinatário do produto ou serviço.

Justamente a judicialização desses conflitos acabou por levantar questionamentos sobre a competência dos juízes estaduais para determinar abstenção de uso, medidas estas que visam também proteger a empresa e a sua função social, entretanto, que esbarram na competência do próprio INPI que outrora conferiu a exploração desses sinais distintivos.

Esse artigo tem por objetivo específico analisar justamente essas as relações conflituosas que envolvem a natureza da intervenção do INPI nos processos de nulidade de registro de marca, bem como nos casos que se apresentam perante a competência dos juízes estaduais e federais na tomada de decisões que envolvam os litígios entre diferentes titulares de marcas registradas perante o INPI.

Essa análise terá como ponto de partida o estudo dogmático relacionado aos procedimentos de registro da marca e sua natureza jurídica como sinal distintivo do empresário, para, em seguida, analisar as formas de conflitos entre marcas registradas e, por fim, debruçar-

Rev. de Direito, Inovação, Propriedade Intelectual e Concorrência | e-ISSN: 2526-0014 | Evento Virtual| v. 6 | n. 1 | p. 55-75 | Jan/Jun. 2020 
se sobre o tema específico da intervenção do INPI e das competências dos juízes estaduais e federais.

Buscar-se-á responder a alguns questionamentos relacionados ao limite da competência dos juízes no julgamento de ações de abstenção do uso de marcas, tais como: qual a natureza da intervenção do INPI nos processos de nulidade de registro de marca? Seria possível ingressar com ação de abstenção do uso de marca em virtude nos casos de semelhanças entre diferentes marcas registradas? Pode o juiz estadual determinar medias antecipatórias ou sentenças de mérito impedido o uso de uma marca registrada pelo INPI? O INPI deve ser intimado a manifestar em todos os processos de abstenção do uso de marcas? Por que a Justiça Federal possui competência para julgamento das ações de nulidade de marcas, o que justifica a atuação?

Considerando a importância da marca para o mercado e as características deste sinal distintivo, a presente pesquisa se faz relevante, especialmente para apresentar um critério objetivo que vise reduzir as discussões sobre a natureza da intervenção do INPI nos processos de nulidade de registro de marca, bem como sobre a competência das decisões judiciais nos demais processos de abstenção do uso de marcas. Tal pesquisa se justifica não somente pelas implicações econômicas que envolvem a exploração da marca e o princípio da efetividade do processo.

A presente pesquisa será realizada de forma qualitativa, analisando para tanto as regras pertinentes à proteção das marcas registradas, bem como as regras processuais de intervenção de terceiros e de fixação de competência, a fim de considerar ao final a natureza da intervenção do INIP nos processos de nulidade de marca e se seria possível manter decisões de juízes estaduais em abstenção do uso de marca quando houver semelhanças entre duas ou mais marcas registradas perante o INPI.

Será utilizado como método de pesquisa o indutivo, a saber, aquele destinado a verificar constatações particulares, e possibilitar que se produzam generalizações sobre o tema. Os procedimentos metodológicos a serem utilizados serão o estudo dogmático jurídico, visto a impossibilidade de um estudo profundo sem que se recorra à lei, doutrina ou jurisprudência neste sentido; e o estudo sistemático, visando interpretar as regras específicas da pesquisa em harmonia com todo o sistema jurídico. 


\section{1 - Aspectos gerais sobre os procedimentos do registro das marcas.}

É possível entender, de modo geral que "todo nome ou sinal hábil para ser aposto a uma mercadoria ou um produto, ou para indicar determinada prestação de serviço e estabelecer a identificação entre o consumidor ou usuário e a mercadoria, produto ou serviço, constitui marca." (SILVEIRA, 2014, p. 14)

As marcas podem se apresentar tanto como símbolos quanto como sinais distintivos, reunindo o patrimônio moral do produto e serviço que indicam. João da Gama CERQUEIRA (1982, p. 773) oferece uma definição clássica em que caracteriza a marca como "todo sinal distintivo aposto facultativamente aos produtos e artigos das industriais em geral para identificá-los e diferenciá-los de outros idênticos ou semelhantes de origem diversa”.

$\mathrm{O}$ registro de marcas no Brasil é feito através de pedido próprio ${ }^{2}$ que deve ser apresentado ao Instituto Nacional da Propriedade Industrial, como requisito atributivo ${ }^{3}$ ao direito de exploração deste sinal distintivo.

Esse pedido pode ser formulado tanto por uma pessoa física, jurídica ou uma coletividade, a qual deverá indicar um titular representante. As pessoas residentes no Brasil podem fazer o pedido diretamente, independente de procuradores, já as domiciliadas no exterior devem constituir representante legal no Brasil, por meio de instrumento de procuração com poderes para receber citações judiciais, conforme estabelece o art. 217 da Lei 9.279/96.

Antes de protocolizar o pedido, o requerente poderá fazer uma pesquisa, de caráter não obrigatório, sobre outras marcas já registradas e pedidos pendentes. Tal pesquisa se mostra relevante, pois é necessário verificar se não há outra solicitação de registro de marca ou marca registrada anteriormente por terceiros.

Isso ocorre porque, como regra geral, a prioridade no registro da marca será deferida àquele que primeiro depositar um pedido. A única exceção a esta regra é o chamado direito do

\footnotetext{
${ }^{2}$ De acordo com o Manual de Marcas do INPI (2019) As petições ou pedidos de registro de marca podem ser encaminhados ao INPI exclusivamente pela internet, por meio do sistema e-Marcas, disponível no portal do INPI, exceto quando a indisponibilidade prolongada do sistema possa causar dano relevante à preservação de direitos.

${ }^{3}$ De acordo com Barbosa (2005, p. 2-3) "O registro de natureza atributiva ocorre quando a propriedade sobre a marca vier a se constituir com a concessão do registro da marca à primeira pessoa que protocolizar a solicitação do mesmo perante um órgão público. Por esse sistema, nenhuma pessoa tem direito ao uso da marca, mesmo se já estivesse fazendo uso dela anteriormente, se esta pessoa não tiver providenciado o pedido de registro desta marca junto ao órgão do Estado competente."
} 
usuário anterior. "Segundo esse princípio, a pessoa que, de boa-fé, usava no país, há pelo menos 6 (seis) meses, marca idêntica ou semelhante, para o mesmo fim ou fins análogos, pode reivindicar o direito de precedência ao registro" (COPETTI, 2007, p. 209).

Em seguida o titular faz o recolhimento da retribuição inicial e apresenta o pedido ao INPI juntamente com as indicações específicas da marca, tais como a classe de produto ou serviço que pertence, as características visuais nominativas, figurativas ou mistas e os produtos ou serviços representativos da atividade que levará a marca.

Essas especificações que devem constar do pedido de registro da marca são indispensáveis, pois decorrem da exigência de novidade relativa da marca em relação a outros produtos idênticos ou semelhantes.

A marca, portanto, deve ser distinta, ou seja, ter um cunho próprio e especial, uma vez que ela é destinada a constituir um sinal de produtos ou serviços. Trata-se dos princípios da distintividade e da especialidade que "concede ao titular o uso exclusivo em sua atividade precípua" (COPETTI, 2010, p. 53) em uma determinada classe de produtos e serviços. "O caráter da distintividade, quase unânime nas definições empreendidas por doutrinadores nacionais e estrangeiros, é condição essencial de validade da marca (ALCANTARA, 2006, p. 40).

Há, portanto, que se destacar que as marcas, de início e à princípio, terão proteção apenas em uma classe específica de atividade, como destaca BASTOS (1997, p. 219):

Nos casos dos produtos compreendidos em setores completamente diversos, como, por exemplo, alimentos e máquinas calculadoras, o titular da marca não poderá impedir que outro utilize o mesmo sinal ou denominação, podendo perfeitamente haver a coexistência de ambos os registros, já que não há risco de confusão.

Depois do protocolo do pedido ele se submete ao exame formal pelo INPI, onde são verificadas as condições necessárias à continuidade do processo, cuja finalidade é identificar qualquer pendência relativa ao procedimento, tal como pagamento em valor incorreto.

Não havendo nenhuma exigência formal, ou tendo sido a mesma cumprida satisfatoriamente, o pedido de registro é publicado na RPI (Revista Nacional da Propriedade Industrial) para que terceiros possam se opor, respeitado o prazo de 60 (sessenta) dias a contar da referida publicação. 
Essa fase tem como objetivo dar publicidade ao pedido do registro da marca, o que permite a terceiros manifestarem-se contrários ao deferimento desse pedido no período de oposição, previsto no artigo 158 da Lei de Propriedade Industrial - Lei 9.279/96. Isso ocorre porque os incisos V e XIX do art. 124 da Lei 9.279/96 vedam o registro de marca que reproduza ou imite marca alheia registrada, elemento característico ou diferenciador de título de estabelecimento, ou nome de empresa de terceiro, suscetível de causar confusão ao consumidor.

Há, desse modo, possibilidade administrativa àqueles prejudicados em utilizarem-se do procedimento de registro do INPI para fazer garantir o seu direito de precedência ou de não concorrência.

Por outro lado, podem diferentes empresários acordarem entre si que suas marcas, mesmo com elementos semelhantes, são passíveis de conviver sem que isso lhes cause prejuízos, ao contrário, em alguns casos a convivência demonstra-se positiva. Desse modo, ao invés da apresentação de oposição, pode ser protocolizado junto ao INPI um "acordo de convivência" ou "acordo de coexistência" que servirá como elemento de subsídio ao exame do pedido de registro da marca.

Decorrido esse prazo, o mérito do pedido será analisado a fim de identificar se a marca pleiteada atende às condições previstas na Lei 9.279/96, tais como: ser um sinal visualmente perceptível; possuir distintividade para destacar o produto ou serviço de outros; e não estar incursa em alguma proibição legal.

Importante destacar que o INPI fará nesta fase uma pesquisa por anterioridades impeditivas e tal pesquisa terá como base apenas a classe de produtos ou serviços indicados no pedido (Resolução INPI/PR n. 248/2019). Realizado o exame de acordo com essas condições, efetua-se o despacho decidindo por seu deferimento, indeferimento ou sobrestamento.

Deferido o pedido, há a constituição de domínio sobre um bem específico, que neste caso se apresenta como um bem incorpóreo fruto de um ato administrativo atributivo em favor de um titular determinado.

O registro validamente expedido pelo INPI é o instrumento que assegura ao titular o uso exclusivo da marca em todo o território nacional, dentro da especialidade da classe, vigorando pelo prazo de 10 (dez) anos, contados da data da concessão, prorrogável por períodos iguais e sucessivos.

Destaca CASTELLI (2006, p.172):

Rev. de Direito, Inovação, Propriedade Intelectual e Concorrência | e-ISSN: 2526-0014 | Evento Virtual| v. 6 | n. 1 | p. 55-75 | Jan/Jun. 2020 
Dentre os direitos conferidos ao titular da marca a partir do registro, o principal deles é o uso exclusivo e consequente exploração da marca no território ou, em outras palavras, o direito de apor a marca nos produtos ou serviços por ela identificados e de coloca-los no comércio, utilizando-a, outrossim, para todos os fins de publicidade e propaganda necessários, relacionados a estes produtos ou serviços.

Poderá também o titular da marca, depois de obtido o registro, ceder o seu direito de propriedade ou licenciar o seu uso para terceiros, sendo sua responsabilidade zelar pela sua integridade material ou reputação, isso tudo pelo prazo de 10 anos contados da data da concessão do registro, prorrogável por períodos iguais e sucessivos.

Concluído o procedimento de registro de marcas o direito é conferido ao seu titular, entretanto, ainda assim é possível o questionamento de sua validade, que se dá através de procedimentos administrativos ou judiciais, os quais serão destacados em seguida.

\section{Processo Administrativo de Nulidade de Registro e Caducidade de Marca.}

Mesmo após a concessão do registro da marca é possível o reconhecimento de sua nulidade através de processo administrativo ou judicial. Dessa forma, pode ser alterada a decisão que concedeu o registro, mediante "Processo Administrativo de Nulidade", ou reconhecimento de "Caducidade", como também a possibilidade de revisão judicial da decisão que concedeu o registro, mediante o ajuizamento de uma "Ação de Nulidade".

Entende Douglas Gabriel Domingues (2009) que a nulidade em regra nasce de um vício substancial nos elementos constitutivos da marca, ou no procedimento formativo o que pode advir de uma violação explícita do texto de lei ou simplesmente relativa à infringência de princípios específicos do direito público. Os efeitos da declaração de nulidade retroagem à data do depósito do pedido da marca, excluindo assim, qualquer direito de exclusividade que o titular da marca obteve nesse período.

O reconhecimento da nulidade poderá inclusive ser parcial, não prejudicando a parte válida da marca. Tal fato está previsto no parágrafo único do art. 165 da Lei 9.279/96 e somente será possível quando a sua composição gráfica "comportar a separação exigida em lei, ou seja, desmembrar a marca de forma tal que, anulada uma parte reste e sobreviva outra não atingida pela nulidade." (DOMINGUES, 2009, p. 554).

Rev. de Direito, Inovação, Propriedade Intelectual e Concorrência | e-ISSN: 2526-0014 | Evento Virtual| v. 6 | n. 1 | p. 55-75 | Jan/Jun. 2020 
Através do processo administrativo de nulidade de marca, o próprio INPI irá decidir que o ato que praticou em conceder o registro é nulo, por ter violado as disposições contidas na Lei da Propriedade Industrial.

Podem requerer a instauração do processo administrativo de nulidade, qualquer interessado que apresente interesse legítimo, tal como ocorre no caso do oferecimento de oposição. Até mesmo o próprio INPI, sem provocação, também poderá instaurar o processo administrativo ex officio.

Esse procedimento administrativo deverá ser instaurado no prazo de 180 dias, contados da concessão do registro e durante sua tramitação não haverá suspensão dos direitos de propriedade da marca, prevalecendo ao titular os efeitos da concessão do registro.

A fundamentação do pedido de nulidade do registro de marca deve estar calcada na violação da norma, entretanto, Michele Copetti destaca também que o pedido deverá levar em conta: "a legitimidade do requerente; os elementos de constituição e as condições de distintividade, disponibilidade, licitude e veracidade do sinal; a existência de eventual violação aos tratados internacionais, e, também o direito de precedência de uso da marca” (2010, p. 137).

Importante destacar que não há previsão na Lei da Propriedade Industrial quanto a superveniência ou não da fundamentação para instauração do processo, o que implica reconhecer que o fato que pode consubstanciar a nulidade não precisa ter ocorrido antes da concessão do registro, tal como ocorre com o reconhecimento de alto renome posterior à concessão do registro que se pretenda anular.

Depois de respeitado o contraditório o Presidente do INPI irá proferir decisão administrativa, contudo, essa decisão não comporta recurso, restando àquele que se sentir prejudicado buscar o pronunciamento judicial, através da ação de nulidade do registro de marca que prescreve em 5 anos, contados da data da concessão. ${ }^{4}$

Outra possibilidade de mudança no registro de marca na esfera administrativa é através da declaração de sua caducidade, que tem motivação em um evento ocorrido após a sua concessão pela sua falta de uso.

Uma vez registrada a marca seu titular tem o dever de utilizá-la, tal como concedida, sem alteração de seu caráter distintivo original, para assinalar os produtos ou serviços para os

\footnotetext{
${ }^{4}$ Tal como indicado nos arts. 173 e 174 da Lei 9.279/96
} 
Almir Garcia Fernandes

quais foi registrada ou então justificar o desuso por razões legítimas, sob pena de ter seu registro extinto. ${ }^{5}$

Ao contrário da nulidade, que tem efeito ex nunc, os "efeitos da caducidade se fazem sentir ex nunc, ou seja, da mesma para a frente, ficando incólume e inatingida a situação anterior à declaração de caducidade” (DOMINGUES, 2009, p. 511). Nesse sentido, o Superior Tribunal de Justiça firmou entendimento de que a declaração de caducidade do registro de marca tem efeitos jurídicos prospectivos, a partir de sua declaração (ex nunc), e não efeitos retroativos (ex tunc) (REsp 1080074/RS, Rel. Ministro LUIS FELIPE SALOMÃO, QUARTA TURMA, julgado em 26/02/2013, DJe 13/03/2013)

A caducidade das marcas está prevista nos artigos 142, III, 143, 144, 145 e 146 da Lei 9.279/96 que poderá ocorrer nas seguintes hipóteses: o uso da marca não tiver sido iniciado no Brasil; o uso da marca tiver sido interrompido por mais de 5 anos consecutivos, ou se , no mesmo prazo, a marca tiver sido usada com modificação que implique alteração de seu caráter distintivo original, tal como constante do certificado de registro.

Em qualquer um desses casos, o prazo para o início do processo é depois de transcorridos os 5 anos, contados da data da concessão do registro, de modo que antes desse período não poderá ser requerida a caducidade dos direitos advindos com a concessão do registro da marca.

A caducidade, tal como a nulidade, poderá ser também parcial, pois será lícito o requerimento de caducidade se o titular deixou de utilizá-la em todos os produtos ou serviços constantes do certificado, em relação aos não semelhantes ou afins daqueles para os quais a marca foi comprovadamente usada

Uma vez deferido o pedido de caducidade, o sinal registrado será cancelado e não mais gozará de proteção contra terceiros interessados. Desse modo, compreende-se que registro da marca, que atende ao princípio da territorialidade, implica na obrigação de explorá-la, garantindo a aplicação única e exclusiva de toda a proteção jurídica no território do Estado onde foi realizado.

Com a efetivação do registro há a concessão de um monopólio temporal que deve ser exercido com exclusividade no respectivo território, havendo instrumentos administrativos

\footnotetext{
${ }^{5}$ De acordo com o Manual de Marcas do INPI (2019).
} 
junto ao próprio INPI para garantir que essa exploração esteja sendo efetivamente realizada e dentro dos parâmetros estabelecidos pela Lei 9.279/96 e convenções internacionais.

Contudo, o titular da marca também dispõe de uma estrutura Judicial para salvaguardar o seu direito de exploração de sua titularidade, pois a nulidade da marca também pode ser requerida através de ação judicial específica, do mesmo modo, também podem ser requeridas medidas judiciais para salvaguardar não só a marca, mas a concorrência desleal, que pode vir a prejudicar não só o seu titular, mas também um significativo número de consumidores.

Parece claro que a preocupação do legislador está adstrita também ao aspecto da preservação do consumidor, tal como se extrai dos princípios inerentes à livre iniciativa (art. 170, inciso V da Constituição da República). Nesse sentido destaca-se o posicionamento de LEONARDOS (1995, p. 15):

Durante longo tempo tem-se buscado uma solução para o problema que extravasa à conceituação da marca notoriamente conhecida, para se chegar à repressão dos atos prejudiciais aos interesses de titulares das marcas e dos consumidores quando se veem lesados por atos menos leais daqueles que procuram no renome de marca já usada para determinada categoria de produtos o sucesso para venda de suas mercadorias em ramo diverso.

Desse modo, percebe-se a importância da proteção das marcas, como instrumento de diferenciação empresarial, de produtos, serviços e proteção do consumidor, possuindo o INPI procedimentos administrativos para a concessão, nulidade e caducidade delas.

Contudo, em muitas situações é necessária a interveniência do Estado através de processos judiciais, quando os procedimentos administrativos no INPI não forem suficientes para solucionar o conflito de interesses dos titulares das marcas.

\section{3 - O processo Judicial de Nulidade e a atuação do INPI como interveniente.}

Conforme destacado anteriormente, a nulidade do ato concessivo do INPI também poderá ser requerida pela via judicial que, embora esteja adstrita ao mesmo fundamento do processo administrativo, contudo, possui maior possibilidade de discussão sobre aspectos específicos e relevantes, não abrangidos pelo INPI.

Rev. de Direito, Inovação, Propriedade Intelectual e Concorrência | e-ISSN: 2526-0014 | Evento Virtual| v. 6 | n. 1 | p. 55-75 | Jan/Jun. 2020 
A sentença a ser proferida nesta ação terá natureza declaratória, pois "o ato administrativo concessivo do registro ao arrepio da lei é nulo de pleno direito, gerando a nulidade absoluta do ato, que não chega a produzir qualquer efeito" (SCUDELER, 2013, p. 222).

A previsão legal que permite a qualquer interessado ingressar em juízo para obter a nulidade do registro da marca está contida nos artigos 173 a 175 da Lei 9.279/96, que determinam inclusive a competência da Justiça Federal para processar o pedido, considerando que a participação do INPI no processo será obrigatória, tendo em vista que foi justamente esse órgão quem proferiu o registro.

Será lícito ao magistrado, nos autos da ação de nulidade, determinar liminarmente a suspensão dos efeitos do registro e do uso da marca, o que implica dizer que o legislador deu autoridade ao magistrado para suspender liminarmente os efeitos do registro e do uso da marca.

Tal fato é de extrema relevância, pois o magistrado passa a ter poderes, tal como indicado no parágrafo único do art. 173 da Lei 9.279/96, de suspender os efeitos de um ato administrativo proferido pela autoridade de registro da marca.

A propositura desta ação deve ocorrer no prazo de cinco anos, sob pena de prescrição, contados da data da concessão do registro pelo INPI, tendo o réu prazo de 60 dias para apresentar defesa.

Destaca-se que não é necessário que o interessado tenha ingressado previamente com processo de nulidade na esfera administrativa, pois a ação pode ser ajuizada mesmo na pendência de julgamento administrativo.

Lembrando ainda que o próprio INPI poderá fazer parte da ação no polo ativo ou será chamado a intervir no feito. Entretanto, não obstante a determinação expressa do legislador da intervenção que está prevista expressamente no art. 175 da Lei 9.279/96, afastando o litisconsórcio, ainda resta controvérsia sobre a forma de participação do INPI.

Isso porque a decisão proferida pelo Magistrado não se refere ao bem da propriedade industrial (a marca), mas sim, interfere diretamente em um ato administrativo praticado pelo INPI, cujo entendimento jurisprudencial dos tribunais da justiça federal era de que esta ação deveria ser proposta contra o titular do registro, tendo como corréu aquela Autarquia Federal. ${ }^{6}$

\footnotetext{
${ }^{6}$ A título de referência ver TRF $2^{a}$ Região - $4^{a}$ T. AgIn 91.02.08324-8 - DJU 16/05/1995. Disponível em http//: www.trf2.jus.br
}

Rev. de Direito, Inovação, Propriedade Intelectual e Concorrência | e-ISSN: 2526-0014 | Evento Virtual| v. 6 | n. 1 | p. 55-75 | Jan/Jun. 2020 
A mudança advinda com a redação do art. 175 da Lei 9.279/96 deixou claro que a participação do INPI nas ações de nulidade deverá ser de mero interventor e não de parte litisconsorte, tendo em vista que os interesses do INPI e do titular da marca no processo são diversos, tal como destaca SOUZA (2005, p. 110):

O INPI como executor das normas de propriedade industrial, deve obedecer a princípios impessoais, como a livre concorrência, o interesse social e o desenvolvimento tecnológico e econômico do País ao passo que o titular e o proprietário têm interesse de ordem particular sobre a propriedade imaterial atacada.

Contudo, a redação do caput do art. 175 da Lei não indica qual será a modalidade de intervenção à qual o INPI deverá atuar no processo.

Para solucionar tal controvérsia devemos em primeiro lugar entender em que situação essa Autarquia ingressaria no processo. A posição mais correta parece ser considerar o INPI como colegitimado, que na definição de Didier Jr. (207, p.310) é:

(...) aquele que, por ser também titular da relação jurídica já deduzida em juízo por outrem ou por legitimação extraordinária conferida pela lei, teria legitimação ativa para propor a mesma demanda já proposta ou, no caso de ser cotitular da relação jurídica, teria legitimação passiva para ter sido demandado.

Dessa forma, nos processos que envolvem a nulidade da marca ou mesmo em qualquer outro processo que envolva a restrição de direitos de registro marcário, a intervenção do INPI poderia ocorrer sob a forma de assistente litisconsorcial, considerando que o que se discute é a validade do ato administrativo outrora praticado.

Uma das soluções apresentadas pela jurisprudência seria incluir o INPI como assistente simples, isso porque o INPI está na custódia de interesses que lhe cabe preservar, ajudando e fortalecendo a parte que é titular do seu direito, decorrente da sua atuação. ${ }^{7}$

$\mathrm{Na}$ assistência simples o terceiro demonstra que sua esfera jurídica será atingida no processo. No caso do INPI o ato administrativo que foi praticado. O fundamento principal para

\footnotetext{
${ }^{7}$ A título de referência ver TRF $2^{\text {a }}$ Região - AC n 12.027/RJ (90.02.002280-0) - DJU 25/03/1993, Disponível em http//: www.trf2.jus.br
} 
que haja assistência simples "é que tenha interesse jurídico em que a sentença seja favorável a uma das partes, a assistida" (GONÇALVES, 2018, p. 190).

Em posição diferente, alguns autores defendem que a assistência não deveria ser simples, mas sim litisconsorcial, como destaca-se Lélio Denicoli Schmidt (1997, P. 215):

Não tendo partido do INPI a iniciativa da demanda, e tendo o autor indicado tal autarquia como assistente litisconsorcial, o juiz deverá reconhecer a necessidade do litisconsórcio e determinar que se promova a citação de tal autarquia como ré. De modo algum o Juiz estará obrigado a intimar o INPI a comparecer como assistente litisconsorcial e este não terá qualquer obrigação ou ônus neste sentido, dada a voluntariedade que é traço característico da assistência, simples ou litisconsorcial.

$\mathrm{Na}$ assistência litisconsorcial o assistente será o "principal atingido com o resultado do processo, porque é dele a relação jurídica material discutida" (GONÇALVES, 2018, p. 195), de modo que aqueles que entendem ser esta a modalidade de intervenção que prevalece, sustentam que a relação jurídica material está relacionada ao ato de registro e não à titularidade da marca. Tal raciocínio não parece ser o mais correto, tendo em vista que se assim o fosse, o INPI deveria ser litisconsorte obrigatório e não interveniente.

Contudo, ainda deve-se lembrar que, a rigor, o assistente não comparece aos autos de forma provocada como se extrai da hermenêutica do art. 175 da Lei 9.279/96. Isso ocorre porque a assistência é uma forma de intervenção de terceiros na qual o assistente atua de forma facultativa, o que representa uma contradição à possibilidade do INPI em atuar sob esta forma, pois o Juiz é obrigado a provocar essa Autarquia, que por sua vez também tem o dever de manifestar-se nos autos.

Ainda, outra questão relevante, está no fato de que tanto na assistência simples como na assistência litisconsorcial, sob a ótica do Direito Processual Civil, o assistente recebe o processo no estado em que se encontra, caracterizando uma divergência com aquilo que está previsto na Lei da Propriedade Industrial, a qual exige a participação desta Autarquia desde a fase postulatória do processo.

Ainda, ao ser chamado a intervir no processo o INPI têm o dever de analisar qual das pretensões (autor ou réu) está mais adequada com a legislação e os tratados internacionais, para que, em seguida, possa posicionar-se na lide.

Rev. de Direito, Inovação, Propriedade Intelectual e Concorrência | e-ISSN: 2526-0014 | Evento Virtual| v. 6 | n. 1 | p. $55-75$ | Jan/Jun. 2020 
Com a promulgação do novo Código de Processo Civil, foi introduzida uma nova forma de intervenção de terceiros que mais se aproxima daquilo que está previsto na Lei 9.279/96, qual seja a figura do amicus curiae.

A intervenção como amicus curiae está prevista expressamente no art. 138 do CPC, permitindo ao juiz ou o relator solicitar ou admitir a participação de pessoa natural ou jurídica, órgão ou entidade especializada, no caso o INPI, no prazo de 15 (quinze) dias de sua intimação, considerando a relevância da matéria, a especificidade do tema objeto da demanda ou a repercussão social da controvérsia, poderá, por decisão irrecorrível, de ofício ou a requerimento das partes ou de quem pretenda manifestar-se.

Trata-se de uma intervenção "peculiar porque ele não intervém nem como parte, nem como auxiliar da parte, mas como verdadeiro auxiliar do juízo", o que parece mais adequado ao caso da intervenção do INPI nas ações de nulidade de marca.

Contudo, também há uma pequena divergência quanto à condição desta Autarquia Federal como amicus curiae, pois essa modalidade de intervenção é admitida para os casos em de maior relevância ou impacto, ou mesmo que possam ter repercussão social, o que não parece o caso da ação de nulidade de marca.

Contudo, a solução que mais parece adequada é considerar a intervenção do INPI no processo de nulidade de marca como amicus curiae, ou ainda inominada ou especial, uma vez que não se adequa às demais hipóteses de assistência.

Portanto, respondendo ao questionamento inicial sobre a natureza da intervenção do INPI nos processos de nulidade de registro de marca é importante frisar que não obstante às mudanças no Código de Processo Civil quanto a atuação de terceiro, tem-se que o raciocínio mais correto seria considerar a atuação do INPI como interveniente inominado, pois as novas formas também não atendem àquilo que está previsto na lei 9.279/96.

\section{4 - As ações de abstenção do uso de marca.}

Os pedidos judiciais que envolvem a abstenção do uso de uma determinada marca por órgão, ou determinada pessoa física ou jurídica, podem estar relacionados a necessidade de cognição sumária do juízo, como medida urgência ou evidência, bem como ligar-se a questões 
que envolvem concorrência desleal entre empresas, uso não autorizado da marca ou mesmo a sua nulidade.

Trata-se, desse modo, de uma medida judicial que no campo material impõe uma obrigação de não fazer, o que confere ao judiciário proferir tutela específica, por meio de ordem de cessação da suposta violação do direito marcário. É uma ação de natureza cominatória, posto que a sentença final poderá impor a uma das partes o dever de não realizar um determinado ato, que sob a ótica do Direito das Obrigações representa uma prestação negativa, um comportamento omissivo do devedor.

Na grande maioria dos casos as ações que requerem a abstenção de uso de marca são cumuladas com pedidos indenizatórios, visto que "da mesma forma que as obrigações de fazer, o que deve ser levado em consideração é se é possível (ou não) restituir as coisas ao status quo ante ou, mesmo assim, se o credor tem interesse em tal situação" (GAGLIANO e PAMPLONA FILHO, 2006, p. 59).

Em muitos processos judiciais que envolvem a abstenção do uso de marca é comum que os requerentes apresentem pedidos em tutela de urgência e evidência visando a proibição de venda de produtos, oferta de serviços, manutenção de sites de internet, busca e apreensão.

Em caso prático de ação de abstenção do uso de marca decidido pelo Tribunal de Justiça da Bahia à Apelação n. ${ }^{\circ}$ 0089667-33.2010.8.05.0001 ${ }^{8}$, podermos observar o exemplo da cumulação do pedido de não fazer com indenização em perdas e danos, em que o Autor requereu a abstenção do uso da marca do Réu, pois, atuavam na mesma atividade econômica (hotelaria). O autor ajuizou a ação alegando atuar no ramo de hotelaria e possuir o direito de exclusividade no uso das marcas registradas "Ponta Verde" e "Ponta Verde Praia Hotel", no entanto o apelado, apesar de constituído após o recorrente, utilizava indevidamente as marcas registradas em seu nome comercial, "Hotel Ponta Verde LTDA".

\footnotetext{
${ }^{8}$ DIREITO EMPRESARIAL. AÇÃO PARA ABSTENÇÃO DE USO DE NOME EMPRESARIAL E MARCA CUMULADA COM REPARAÇÃO DE DANOS. SENTENÇA JULGANDO IMPROCEDENTES OS PEDIDOS. APELAÇÃO. CONFLITOS ENTRE NOMES EMPRESARIAIS E ENTRE MARCA E NOME EMPRESARIAL. PRINCÍPIOS DA TERRITORIALIDADE E DA ESPECIALIDADE. PEDIDO INDENIZATÓRIO. PRESCRIÇÃO. SUCUMBÊNCIA RECÍPROCA. RECURSO CONHECIDO E PROVIDO EM PARTE. Disponível em: https://jurisprudencia.s3.amazonaws.com/TJ-BA/attachments/TJBA_APL_00896673320108050001_1dd12.pdf?Signature=OQfft0ob18JHEF81xtRMOI7mNLY\%3D\&Expires=1 536261531\&AWSAccessKeyId=AKIAIPM2XEMZACAXCMBA\&response-content-type=application/pdf\&Xamz-meta-md5-hash=89a56477e9ecf921c331c757b1bdb673.
} 
Esse exemplo destacado demonstra que a decisão foi tomada em juízo estadual e não federal, posto que envolve apenas interesses dos litigantes, sem envolver INPI, Autarquia Federal.

Quando as decisões do juiz estadual estão restritas aos casos práticos de utilização indevida da marca por terceiros não autorizados não há dúvidas relevantes de que a competência está sendo exercida pelo órgão judicante correto.

Contudo, se os litigantes forem titulares de marcas diversas, ambas registradas no INPI, seria a justiça estadual competente para julgar o litígio? Poderia o juiz estadual determinar medias antecipatórias ou sentenças de mérito impedido o uso de uma marca registrada pelo INPI?

As respostas a esses questionamentos começam pela análise do objeto de discussão da lide, se envolve uma simples questão de concorrência desleal ou se de nulidade parcial da marca.

Isso porque a proteção jurídica do conjunto-imagem da marca registrada está situada no âmbito da concorrência desleal, avesso ao interesse institucional do INPI. Em muitos casos a discussão envolve o conjunto visual através do qual o produto ou serviço é apresentado aos consumidores, tornando-se característico de determinada empresa. A esse conjunto visual dáse da denominação de trade dress.

Conforme definido por Tinoco Soares (2004, p.213), o trade dress é “a imagem total do negócio; num sentido bem geral é o 'look and feel', isto é, o ver e o sentir do negócio”. Resta desse modo evidenciado que nenhum interesse do INPI pode se extrair de qualquer decisão judicial que envolva apenas as violações desse conjunto.

De modo que só haverá interesse dessa Autarquia Federal nas hipóteses em que há discussão sobre a nulidade absoluta ou relativa da marca.

Essa questão foi objeto inclusive de discussão no STJ e a tese firmada sobre esse assunto foi a seguinte:

As questões acerca do trade dress (conjunto-imagem) dos produtos, concorrência desleal, e outras demandas afins, por não envolver registro no INPI e cuidando de ação judicial entre particulares, é inequivocamente de competência da justiça estadual, já que não afeta interesse institucional da autarquia federal. No entanto, compete à Justiça Federal, em ação de nulidade de registro de marca, com a

Rev. de Direito, Inovação, Propriedade Intelectual e Concorrência | e-ISSN: 2526-0014 | Evento Virtual| v. 6 | n. 1 | p. 55-75 | Jan/Jun. 2020 
participação do INPI, impor ao titular a abstenção do uso, inclusive no tocante à tutela provisória. ${ }^{9}$

Há então de se concluir que nas ações de abstenção de uso de marca que não envolvem pedido de nulidade, total ou parcial, e que o objeto da discussão esteja relativo a perdas e danos, indenização, concorrência desleal, utilização indevida da marca, desvio desleal de clientela, busca e apreensão de produtos, a competência para julgamento será sempre da Justiça Estadual, sem a necessidade de intervenção do INPI, posto que não há qualquer violação de suas prerrogativas.

Por outro lado, será de competência da Justiça Federal e com intervenção obrigatória do INPI, por determinação legal, as lides que versarem sobre pedidos de abstenção de uso de marca que sejam cumulados com a nulidade total ou parcial da marca.

Acreditar que o INPI deveria participar em todos os processos de abstenção do uso de marca seria o mesmo que exigir que os cartórios de registro de imóvel intervissem em todas as ações de registro de imóvel. Ademais, sua participação nas ações de nulidade ocorre em virtude de expressa determinação legal, sob pena de nulidade do processo.

Portanto, responde-se de forma negativa ao questionamento formulado inicialmente, se o INPI deveria ser intimado a manifestar em todos os processos de abstenção do uso de marcas, pois que nas ações de competência da justiça estadual sua manifestação é desnecessária por se tratar de questões de interesse particular.

\section{CONCLUSÃO}

De todo o exposto, podemos concluir ao final que as marcas se apresentam como instrumentos de significativa importância no desenvolvimento da atividade empresarial, cujo registro é ato exclusivo do Instituto Nacional da Propriedade Industrial, Autarquia Federal com prerrogativas de conceder e cancelar o direito de propriedade sobre esse bem da propriedade industrial.

Após a conclusão do registro foi evidenciado que é possível aos interessados, ainda de forma administrativa, requerer a nulidade ou caducidade do registro da marca, resguardados

\footnotetext{
${ }^{9}$ Disponível em: http://www.stj.jus.br/repetitivos/temas repetitivos/pesquisa.jsp. Acesso em 15/02/2020.
} 
os requisitos temporais e a demonstração de violação da Lei 9.279/96, mesmo que por fato posterior.

Desta forma, o presente artigo buscou enfatizar que as marcas se caracterizam como bens patrimoniais, obtidas através de registro no Instituto da Propriedade Industrial, cujas atribuições podem inclusive cancelar o registro após a sua expedição por nulidade ou caducidade.

Destacou-se que a nulidade da marca também pode ser requerida por via judicial, cuja competência de julgamento será da Justiça Federal, podendo inclusive o INPI figurar no polo ativo da lide. Contudo, quando o INPI não for parte deverá intervir obrigatoriamente no feito sob pena de nulidade do feito.

Restou demonstrado que a natureza da intervenção do INPI nos processos de nulidade de marca deve ser feita de forma inominada, posto que não se adequa em nenhuma das hipóteses previstas no atual Código de Processo Civil, sendo a figura do amicus curiae aquela que mais se aproximaria de uma modalidade de intervenção da qual prevê a Lei 9.279/96.

Por fim, foi demonstrado também que os processos de abstenção do uso de marca não estão restritos apenas à pedidos de nulidade total ou parcial de marcas registradas. A abstenção do uso de marca trata-se de uma obrigação negativa que será imposta em desfavor de empresários, com ou sem marca registrada, contudo a competência para julgamento dessas causas estará a cargo da Justiça Estadual, posto que não há interesse do INPI em questões particulares.

Os questionamentos iniciais foram respondidos demonstrando que a natureza da intervenção do INPI nos processos de nulidade de registro de marca é de interveniente inominado. Que é possível ingressar com ação de abstenção do uso de marca em virtude nos casos de semelhanças entre diferentes marcas registradas tanto na Justiça Comum Estadual, quanto na Justiça Federal, contudo, se o objeto do pedido envolver a nulidade total ou parcial da marca deverá ser decido por esta última. Ainda, restou demonstrado que o juiz estadual pode determinar medias antecipatórias ou sentenças de mérito impedido o uso de uma marca registrada pelo INPI e que essa Autarquia não será intimada a manifestar em todos os processos de abstenção do uso de marcas, pois que somente na Justiça Federal é possível discutir assuntos relativos ao registro da marca, posto que trata-se de ato praticado por Autarquia Federal. 
Almir Garcia Fernandes

Dessa forma concluiu-se o presente trabalho sem a pretensão de esgotar todo o assunto, mas apenas contribuir para outros debates acerca do tema.

\section{BIBLIOGRAFIA}

ALCANTARA, Fabricia. A proteção das Marcas no Direito Brasileiro. Revista Brasileira de Direito Internacional. Curitiba, v.4, n.4, jul/dez 2006, p. 36 a 65.

BARBOSA, Denis Borges. Tratado da Propriedade Intelectual. v. I, Rio de Janeiro: Lúmen Júris, 2013.

Direito de Precedência ao registro de marcas. 2005.

Disponível em: http://denisbarbosa.addr.com/precedencia.pdf. Acesso em 10 de janeiro de 2020.

BASTOS, Aurélio Wander. Dicionário Brasileiro de Propriedade Industrial e Assuntos Conexos. Rio de Janeiro: Lúmen Júris, 1997.

BRASIL. Instituto Nacional da Propriedade Industrial. Manual de Marcas do INPI. 3 ed. 2019. Disponível em: http://manualdemarcas.inpi.gov.br. Acesso em 10 de janeiro de 2020.

CASTELLI, Thais. Propriedade Intelectual. O Princípio da Territorialidade. São Paulo: Quartier Latin, 2006.

CERQUEIRA, João da Gama. Tratado da Propriedade Industrial. 2 ed. v.2. São Paulo: Revista dos Tribunais, 1982.

COPETTI, Michele. Registro de Marcas - Propulsor para o Desenvolvimento? BARRAL W e PIMENTEL, L.O. (org.) Propriedade Intelectual e Desenvolvimento. Florianópolis: Boiteux, 2007.

Afinidade entre marcas: uma questão de direito. Rio de Janeiro: Lumen Juris, 2010.

DIDIER JUNIOR, Fredie. Curso de direito processual civil. 9. ed. v. 1. Salvador/BA: Juspodivm, 2007.

DOMINGUES, Douglas Gabriel. Comentários à lei da propriedade industrial: lei 9.279/96 de 14 de maio de 1996. Rio de Janeiro: Forense, 2009.

Rev. de Direito, Inovação, Propriedade Intelectual e Concorrência | e-ISSN: 2526-0014 | Evento Virtual| v. 6 | n. 1 | p. 55-75 | Jan/Jun. 2020 
GAGLIANO, Pablo Stolze e PAMPLONA FILHO, Rodolfo. Novo curso de direito civil: obrigações. 7 ed. v. II. São Paulo: Saraiva, 2006.

GONÇALVES, Marcus Vinícius Rios. Novo curso de direito processual civil. 15 ed. v.1. São Paulo: Saraiva, 2018.

LEONARDOS, Luiz. A superação no conceito de notoriedade na proteção contra as tentativas de aproveitamento de marcas alheia. Revista da associação brasileira de propriedade industrial. São Paulo: ABPI, nº 19, p. 13-16 nov/dez.1995

SCHIMDT, Lélio Denicoli. O INPI nas Ações de Nulidade de Marca ou Patente: Assistente, litisconsorte ou Fiscal da Lei. Revista da ABPI. Rio de Janeiro, n26, jan/fev. 1997.

SCUDELER, Marcelo Augusto. Do Direito das marcas e da propriedade industrial. Campinas, SP: Servanda Editora, 2013).

SILVEIRA, Newton. Propriedade Intelectual. 5 ed., São Paulo: Manole, 2014.

SOARES, José Carlos Tinoco. Concorrência desleal: Trade dress e/ou conjuntoimagem. São Paulo: Ed. do Autor, 2004

SOUZA, Antônio André Munis de. O INPI como interveniente especial nas ações de nulidade - nova interpretação conforme a lei da propriedade industrial. Revista CJE. Brasília, n. 28, p. 109 - 115, jan./mar. 2005. Disponível em: https://revistacej.cjf.jus.br/revcej. Acesso em 20 de janeiro de 2020.

Rev. de Direito, Inovação, Propriedade Intelectual e Concorrência | e-ISSN: 2526-0014 | Evento Virtual| v. 6 | n. 1 | p. 55-75 | Jan/Jun. 2020 